\title{
WHEN TO CALL THE CUSTOMER? TIMING OF CUSTOMER INVOLVEMENT IN THE DEVELOPMENT OF NEW PRODUCTS AND SERVICES
}

\author{
SABIT VESELAJ* and MAGNUS THOR TORFASON \\ University of Iceland \\ Faculty of Business Administration \\ Saemundargata 2, 101 Reykjavík, Iceland \\ *sav4@hi.is
}

Published 22 November 2018

\begin{abstract}
Involving customers in the development of new products and services helps firms understand customer needs, increasing the likelihood of meeting those needs and expectations. Although a large body of literature addresses the implications of customer involvement for project performance, the results of previous research are somewhat inconsistent. This paper explores this issue by examining the differing impact of customer involvement on the development of new products and new services. We propose that the role of customer involvement differs for these two types of innovations, with involvement in the early stages more important for products and involvement in the launch stage more important for services. Our results, based on a comprehensive dataset on customer involvement in innovation, are consistent with such a pattern, suggesting that more attention should be paid to the conditional benefits of customer involvement in different types of solution development.
\end{abstract}

Keywords: Customer involvement; products; services; stages of development.

\section{Introduction}

In a complex and very fast-changing business environment, it is imperative for firms to identify, absorb, and integrate knowledge from external sources (Cohen and Levinthal, 1990). One approach to doing that, recently highlighted by a number of studies, is customer involvement in the innovation process. Customer involvement in the development of new products and services has been recognized

This is an Open Access article published by World Scientific Publishing Company. It is distributed under the terms of the Creative Commons Attribution 4.0 (CC-BY) License. Further distribution of this work is permitted, provided the original work is properly cited. 
as a critical factor for firms' success in current socio-economic transformations (Alam, 2002, 2006; Alam and Perry, 2002; Prahalad and Ramaswamy, 2004a, 2004b; Vargo and Lusch, 2004a). Firms can benefit in many ways from involving customers in the innovation process, including cost reduction, speed to market, quality of products and services, improved performance in the development of new products and services (Chang and Taylor, 2016), and improved product outcomes (Al-Zu'bi and Tsinopoulos, 2012; Mahr et al., 2014).

Other studies, however, find no impact of customer involvement on new product development (NPD) performance, or even a negative effect (Menguc et al., 2014; Ordanini and Parasuraman, 2011). The inconsistent findings suggest the need for better understanding of the role of customer involvement and the conditions under which customer involvement is more or less beneficial for firm performance.

In this paper, we bring attention to how customer involvement operates differently in different types of innovation processes. In particular, we focus on the distinction between product and service development. In product development, much of the adaptation to customer requirements needs to take place early in the process, whereas adaptation is more difficult and costly later on, once the product has been solidified. In service development, interaction between the customer and the supplier is inherent in the use of the service at any stage, and adapting the service to customer input throughout the entire project is generally more feasible. Therefore, we argue that it is important to examine the impacts of customer involvement at different stages of the development of products on one hand and services on the other.

The paper is structured as follows. First, we review the literature on customer involvement in the development of new products and services, and the implications of this involvement. Second, we develop hypotheses regarding customer involvement in developing new products and services in different stages of the development process. Third, we present the methodology and empirical results. Fourth, we conclude with a discussion of the results, limitations, and future recommendations.

\section{Conceptual Framework}

A large body of literature addresses external sources of knowledge (e.g., customers, suppliers, and other organizations or stakeholders) in the development of new products and services. Ind and Coates (2013) suggest that although involving customers in the innovation process in developing new products and services is a new phenomenon in market research, there are examples of customers being involved in creating new products and services since the 1970s. This approach has 
been referred to as the "Scandinavian approach" or "participatory design" and is characterised by involving customers throughout the process and giving them power in designing what they want to use.

Several studies argue that involving customers in the innovation process has a considerable impact on the firm as a provider of services or products and on the customer as a buyer or recipient of the product or services (Chang and Taylor, 2016; Matthing et al., 2004; Wang et al., 2013). According to Hoyer et al. (2010), the main motivations for the participation of customers in the innovation process are financial rewards, social benefits, product, or service knowledge during the involvement process, enjoyment, and feeling of being part of society. These studies tend to focus on the benefit of customer involvement from the perspective of the firm and examine how customer involvement affects the performance of the firm or of individual projects.

In these studies, involvement has been conceptualised in various ways. For example, Alam (2006, 2013) uses the term "customer interaction," and Dadfar et al. (2013) and Sigala (2012) use the term "customer involvement." Blazevic and Lievens (2008), in contrast, stress that customers are "co-creators of knowledge" in service firms. Carbonell et al. (2009) define customer involvement as "the extent to which service producers interact with current (or potential) representatives of one or more customers at various stages of the new service development process" (p. 537). Edvardsson et al. (2010) follow a similar approach, referring to customer involvement as "being proactive and coming close to customers in order to learn from and with them throughout the service innovation process and beyond what traditional focus groups, observations, questionnaires and interviews can provide" (p. 304), and portraying the customer as a buyer, a subject of interest, a provider of information, and a co-developer (p. 310).

Lengnick-Hall (1996) takes a producer's perspective and concludes that customers can be viewed as a resource, as a co-producer, as a buyer, as a user, and as a product, while Good (1990) takes a marketer's perspective and defines involvement as "the amount of participation perceived by the consumer to be required to engage in a particular activity or service" (p. 4). Finally, and in a similar vein, Dabholkar (2015, p. 483) defines customer participation as "the degree to which the customer is involved in producing and delivering the service." Summarizing these definitions, the two main perspectives that emerge are those that emphasize the role of the customer as an idea provider and co-producer and those that emphasize the traditional role of the customer as a buyer and user.

Although studies define customer involvement in different ways, a common conclusion is that by involving customers in the innovation process, firms will be able to understand not only current customer needs, but also future customer needs and latent needs. Hoyer et al. (2010) examined what kinds of customers to involve 
in the innovation process and suggested innovators, lead users, emergent consumers, and market mavens as the most promising groups. Matthing et al. (2004) find customers' ideas are more innovative than those of professional service developers (p. 490). Similarly, Herstatt et al. (2006) find that regular contacts with customers in different forms (direct contacts, assessment of customer complaints, and surveys with customers) had a positive impact on the firm's success. Nishikawa et al. (2013), studying the Japanese firm Muji, find that aggregate sales of products that were developed as a result of users' ideas were five times higher than the sales of products created from professional designers' ideas. Furthermore, the study suggested that ideas generated by users tend to be more valuable than ideas generated by designers in terms of market performance metrics. Finally, the study found that products that were generated by users had a significantly higher survival rate (years in use) than products generated by designers.

Although many studies find a positive impact of customer involvement on NPD performance, other studies indicate that customer involvement has no effect, or even that the impact is negative (Carbonell et al., 2009; Gassmann et al., 2010; Lin et al., 2013; Menguc et al., 2014; Ordanini and Parasuraman, 2011). Furthermore, Ulwick and Leonard (2002) underscore that customers are not experts and do not know what they want, while Thomke and von Hippel (2002) highlight that even if customers know what they need and want, they cannot articulate their needs explicitly. Moreover, Knudsen (2007) argues that customer involvement has a negative effect on innovative performance, even if customers are more likely to be involved in the innovation process than other external partners.

Numerous reasons have been proposed for the reduced benefits of customer involvement. Gassmann et al. (2010) note a number of ways in which customer involvement in the early stages can have negative side effects, including overreliance on customer views and interests, the possibility of over-customising the offering so that it serves only a niche market, and a loss of know-how. Menguc et al. (2013) examine how innovation capability moderates the benefits of customer involvement, and Lin et al. (2013) focus on the level of innovativeness in the same context. Lin et al. find that the benefits of customers as co-developers in the later stages is greatest when the innovation level is high. However, they find that the value of the customer as an information source in the early stage is greater when the innovation level is low. More recently, Candi et al. (2015) argue that the role of customer as a co-creator of value is lower for innovations that address sentiments or emotions (hedonic radicalness) and higher for innovations that address specific functionality needs (utilitarian radicalness).

In line with other studies that examine the different effects of customer involvement depending on the circumstances, we examine how the benefit of customer involvement depends on the fit between what is being developed and how 
the customer is brought into that process. In particular, we focus on the distinction between products on one hand and services on the other.

\section{The distinction between products and services}

The idea that products and services differ in fundamental ways is not new. As early as 1966, Rathmell emphasised that goods are to be treated as a noun and consequently identified as a thing, while services are to be treated as a verb and therefore, as an act (Rathmell, 1966). In addition, he identified 13 characteristic differences between manufacturing goods and services. He highlighted the importance of services although at the time services represented only $30-40 \%$ of the economic activity, compared to more than $70 \%$ in current developed western economies (Ostrom et al., 2010). Services are highly important for current economies, and account for three-quarters of jobs and the gross domestic product (GDP) in developed economies (Gallouj and Savona, 2010; Ostrom et al., 2010; Salter and Tether, 2006).

The most obvious differences between manufactured products and services are four characteristics known as intangibility, heterogeneity, inseparability, and perishability (IHIP) highlighted by Kotler et al. (2005). Kotler et al. define services as "any activity or benefit that one party can offer to another which is essentially intangible and does not result in the ownership of anything" (p. 625). An implication of this is that services "cannot be seen, tasted, felt, heard or smelt before they are bought" (p. 626). Other key characteristics include inseparability, the requirement that services are produced and consumed simultaneously; heterogeneity (or variability), the issue that the quality of service is much more variable than the provision of a product influence the success for service providers; and perishability, the absence of the possibility to keep services for later use.

The IHIP definition of services focuses largely on their characteristics and delivery circumstances. Vargo and Lusch, however, focus more on the role of the service provider. They define services as "the application of specialized competences (skills and knowledge), through deeds, processes, and performances for the benefit of another entity or the entity itself (self-service)" (Vargo and Lusch, 2004a, p. 2; Vargo and Lusch, 2004b, p. 2). This approach highlights the skills and knowledge that are required to provide a given service.

Although these characteristics of services have been highlighted, current researchers have argued that instead of treating products and services as completely separate, it would be beneficial to study them using an approach that is integrated, while accounting for the differences between the two (Vargo and Lusch, 2004a). There are two main approaches to integrating research on products and services in the context of the development of new offerings. 
On one hand, the offering itself may combine the characteristics of a product and a service through servitisation or other means (Baines et al., 2009; Reim et al., 2015). Companies increasingly offer such hybrids, by offering service solutions that complement existing products in an integrated manner or by switching from the final sale of products to a service-based business model that delivers the benefits of the product in an integrated manner. An example is Rolls Royce, which shifted from selling aircraft engines to viewing the key offering as a "propulsion service," where the engine is only one part of an integrated solution that includes maintenance and data analytics ( $\mathrm{Ng}$ et al., 2012).

On the other hand, important insights can also be gained by including data on both products and services in a given study, as Gustafsson et al. (2012) did when analysing the experiences of product development managers and service development managers as pertaining to communication with customers during the development of new offerings. In this study, we use this approach, and in particular, we hypothesise that there may be differences in the optimal approach to customer involvement when developing new products versus services.

\section{Hypothesis Development}

In this study, we build on the definition of customer involvement provided by Carbonell et al. (2009) in their study of the development of new services. Although they focus on services, we feel that the core of the definition applies to the development of new offerings in general. Paraphrasing their original definition, we refer to customer involvement as the extent to which the providers of a new offering interact with current (or potential) representatives of one or more customers at various stages of the new offering development process. This use of the term customer involvement is similar to what Chang and Taylor (2016) refer to as customer participation, and other authors have referred to as customer interaction or customer partnerships (Carbonell et al., 2009). As Carbonell et al. note, however, customer involvement is dissimilar from the phenomenon of mass customisation as defined by Kaplan and Haenlein (2006). Inevitably, the specific activities that developers and customers engage in during the process of customer involvement differ according to the type of offering being developed and the stage of development during which the involvement occurs.

\section{Customer involvement in the idea generation phase}

Idea generation represents the first stage of innovation, where ideas come from different sources. Activities such as screening, evaluating, and choosing the most 
promising ideas for further development are performed during this stage. Fuchs and Schreier (2011) argue that firms that engage with customers and encourage them to participate actively in NPD, such as in developing and selecting ideas for further development, have a competitive advantage compared to firms that do not empower customers in such a manner. Similarly, Kristensson et al. (2004) argue that ordinary users generate ideas that are substantially more original and beneficial than professional designers and advanced consumers. This view is in line with the view of other researchers, such as Magnusson (2003) and Matthing et al. (2004). However, some studies have questioned the view that involving customers in the process of developing new products and services always positively influences the success of new products and services, and therefore, the overall performance of the firm, asserting that customers are not experts, that they do not know what they want (Ulwick and Leonard, 2002), and that even if customers know what they need and want, they cannot articulate their needs explicitly (Thomke and von Hippel, 2002).

A number of researchers have examined the different costs and benefits of customer involvement in different stages. For example, Gruner and Homburg (2000) posit that customer involvement is useful in the early stages that involve idea generation and again in later stages, but less so in the middle stages that involve project definition and engineering. Consistent with this view is the study conducted by Chang and Taylor (2016). Chang and Taylor argue that customer participation in the innovation process is critical, especially in the idea generation and launch phases. In addition, their study showed that customer involvement is more important for small and medium firms than for large ones.

Given that there are both costs and benefits of involving customers, it is especially important that customer involvement takes place at the point in the process when the benefits are maximised and the costs are minimised. Witell et al. (2014) found that acquiring information from customers in the early stages (including idea generation) of NPD is particularly important for firms involved in manufacturing goods, because of the importance of determining early on what problem the product solves, as opposed to how the problem gets solved. Examining potential negative effects of customer involvement, Gassmann et al. (2010) point to potential over-reliance on customer views, and the possibility of over-customising the offering based on early-stage input. Given the amorphous nature of services and the temptation to adapt them to each instance, this threat of over-customisation may be particularly salient when developing new services. Finally, Lin et al. (2013) demonstrate that in low-uncertainty offerings, where customers have a better ability to visualise the innovative solution early on, the benefits of early involvement is greater. Although Lin et al. did not compare products and services, the study results are in line with the idea that products, 
because they need to be defined early during the process and because they can be more readily visualied by the customer, benefit more from early-stage customer involvement.

Building on these results of previous research, we posit that because some features of products need to be fixed very early during the process, customer input in those features is highly valuable early during the idea stage, but that the benefit is not as great if the input comes later in the process. The solidification of products early on, in particular when coupled with the widespread use of early prototypes, can make it easier for customers to evaluate the products and provide benefits. Services, in contrast, can be adapted even very late in the development process or even through the launch, and this adaptability makes it possible for services to benefit from customer involvement late in the process. At the same time, the adaptability of services makes them especially susceptible to the threat of overcustomisation due to early-stage customer involvement. Because of these distinctions, we argue that although early customer involvement can benefit the development of new offerings in general, early involvement is especially important for product-focused firms:

Hypothesis 1: Customer involvement in the idea generation stage positively affects project performance.

Hypothesis 2: For product-oriented firms, customer involvement in the idea generation stage is more important than customer involvement in the launch phase.

\section{Customer involvement in the launch phase}

Customer involvement in the later stages (the launch phase) of the innovation process has been found to have a positive impact for manufacturing firms and firms that work in service industries (Gruner and Homburg, 2000). Alam and Perry (2002) argue that customer input in developing new services has a positive effect in developing superior services, indicating that firms provide higher service quality for customers by involving them in the process in general. However, many of the mechanisms proposed above that apply to early-stage involvement work differently or not at all for the launch stage.

According to Witell et al. (2014), customer involvement in the launch phase of the development of new services enables firms to have more control over the process and in this way reduce the uncertainty. Services are more malleable throughout the development process, making it possible to incorporate customer input late in the process, even during the launch, and interaction with the customer is a very natural part of launching a service. However, the threat of over- 
customisation of services that applies in early-stage involvement (Gassmann et al., 2010) is less of an issue during the later stages, after the question of what to solve has been answered, and the focus is on how to solve it (Witell et al., 2014). This is also in line with the perspective of Lin et al. (2013), who find that in uncertain and amorphous innovations, it is most important to get user input late in the development of a new offering.

Taken together, the implication is that the costs of involving customers in the development of new services are lower in the later stages, when the threat of overcustomisation is alleviated and when customers are in a better position to visualise the service. At the same time, because of the ability to adapt services throughout the process, to a greater extent than products, the benefits of late-stage involvement are high. Therefore, we predict that although customer involvement in the later stages is beneficial for the development of new offerings in general, this is especially true for service-focused firms:

\section{Hypothesis 3: Customer involvement in the launch stage positively affects project performance.}

Hypothesis 4: For service-oriented firms, customer involvement in the launch stage is more important than customer involvement in the idea generation stage.

\section{Summary of hypotheses and variable dependencies}

The hypotheses presented above can be visualised through the diagrams displayed in Fig. 1. Hypotheses 1 and 3 are reflected in the predicted positive relationships between customer involvement in the idea generation and launch stages with the firms' overall performance. Hypothesis 2 is reflected in the presence of two plus signs for the relationship between involvement at the idea generation stage and performance for products, indicating that this relationship is expected to be stronger than for involvement in the launch stage, as well as the presence of two

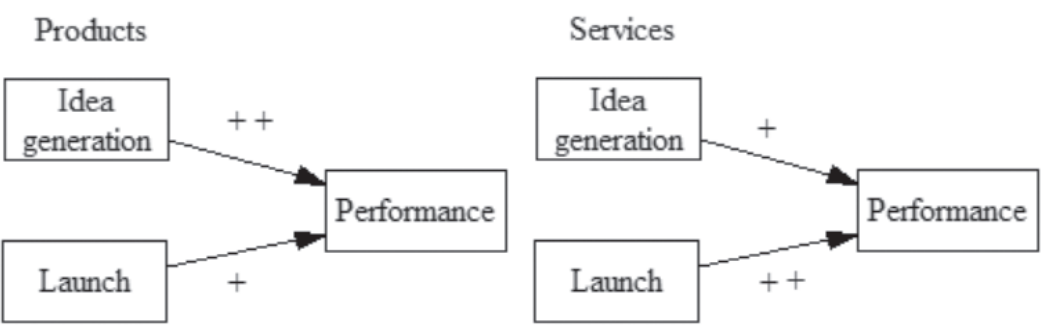

Fig. 1. Theoretical model(s) and hypotheses. 
plus signs for the relationship between customer involvement and performance for services.

\section{Methodology}

The hypotheses above were tested using data collected about innovation projects, using a survey that was administered to managerial employees of firms involved in the development of new offerings. Individual variable constructs are discussed in the section below on variables, and we include a detailed overview of the survey questions, along with validity and reliability measures, in Appendix C. Survey respondents were chosen based on a list of firms classified as manufacturing and service firms, which was obtained from Statistics Iceland. A sample of respondents in Icelandic small and medium enterprises (SMEs) involved in business-toconsumer offerings (B2C) participated in the study.

The firms belong to a wide range of industry sectors, such as food, manufactured products, information technology, services, and tourism. To collect data, a total of 272 firms selling products or services were contacted; each firm was initially contacted by phone. If they agreed to participate, they received a link to complete the survey online. A total of 208 questionnaires were returned, which indicates a response ratio of $76 \%$. Participants who completed the questionnaire were high-level managers at the firms, either chief executive officers (CEOs) or managers responsible for the development of new products and services in the firms. Questionnaire items were generally structured as five-point Likert-type questions. Questions and answers were originally in Icelandic but were translated by the authors for inclusion in the paper (see Appendix C).

We focused on SMEs because they are attractive candidates in many ways to answer the research questions. First, SMEs are more likely to focus on a coherent set of goods or services, as opposed to multi-divisional firms, which may have a portfolio of offerings across different divisions. Large and mixed portfolios within a single firm would have made it difficult to classify firms as focused on either products or services. Second, SMEs are highly relevant because they represent the vast majority of companies in Iceland, as well as globally. Finally, Chang and Taylor (2016) argue that the benefits of customer involvement in NPD are greater for small firms than for large ones, and therefore, small firms present a good opportunity to study the patterns of such benefits.

We used SPSS and R to examine relationships between variables, present them graphically, and test the hypotheses using ordinary least squares (OLS) linear regression models. The variable construction is described in detail in the following section. 


\section{Variables}

Scales for this paper consisted of the items that had been previously utilised in the literature, with slight modifications for the purposes of this study. We performed reliability and validity testing for variable constructs as appropriate. For measure validation, we used confirmatory factor analysis. For all constructs with more than one item, the alpha coefficient of reliability was calculated and evaluated. For the majority of constructs, the alpha coefficient was higher than 0.7 , suggesting a strong internal consistency among items that were used. A detailed overview of the validity and reliability measures is presented in Appendix C.

The dependent variable in the analysis was the Overall Performance variable. This variable captures how well a firm's new products or services performed in the market. For the construction of this variable, we relied on scales from Lai and Wong (2012), Ku et al. (2016), and Lin et al. (2013), with some modifications. This variable was constructed using four questionnaire items (Cronbach's alpha coefficient $=0.75$ ), which were combined using the mean of the four items. Respondents were asked, "To what extent do you agree with each of the following statements," with five options ranging from "Strongly disagree" to "Strongly agree." The four statements were the following: (1) "The quality of our products was higher than of our competitors," (2) "The financial performance of our NPD was better than of our competitors," (3) "We developed products faster than our competitors," and (4) "The new products that we launched on the market were more innovative than the products of our competitors."

The key independent variables relate to the level of customer involvement in different stages of product and service development. The questions regarding customer involvement build on the definition used by Carbonell et al. (2009) and others, as discussed previously. Regarding customer involvement in idea generation, the development stage, and the launch stage, a single item question was used for all phases, starting with a statement about customer involvement, "Please indicate the amount or extent of involvement of customers in relation to the following," followed by statements regarding the different phases, that is, (1) "Participation of customers in the generation of ideas for new products and services," (2) "Participation of customers in the development stage of new products and services," and (3) "Participation of customers in the launch stage of new products and services." Options for responses ranged from "To a very small extent" to "To a very great extent."

Although data were collected for three phases (idea generation, the development phase, and the launch phase), preliminary analysis revealed that the responses regarding the idea generation phase and the development phase were highly correlated. Due to this high correlation, we decided to combine these two 
variables into one variable (see Appendix A for further diagnostic analysis related to this decision). This resulted in two variables that were used for the regression analysis, Involvement in IG and Dev Phases and Involvement in the Launch Phase. Because we used only one question item for involvement in the launch phase, we were unable to calculate reliability measures for that variable, but for involvement in idea generation and development, we calculated those measures and found very high reliability (Cronbach's alpha coefficient 0.97 ). We report descriptive statistics for the underlying measures below.

Competitive intensity was added as a control variable. This variable construct follows the scales used by Jaworski and Kohli (1993), and Avlonitis and Spiros (1999), with slight modifications. Five items were used to construct this variable (Cronbach's alpha coefficient was 0.61 ). The following question was asked for this variable: "To what extent do you agree with each of the following statements?" Five response options ranged from "Strongly disagree" to "Strongly agree." The five statements were the following: (1) "there is intense competition in the market in which we operate," (2) "price wars are common in the market in which we operate," (3) "competitors find it easy to imitate one another in the market in which we operate," (4) "we hear about new competitors daily," and (5) "our competitors are relatively weak" (reverse coded).

In examining the validity of these variables, we found item number 5 ("our competitors are relatively weak") correlated much more weakly than the other four. The Cronbach alpha coefficient was only 0.68 when this item was included but 0.77 when the item was excluded. Examining the different items, we found that the fifth item pertains more to the relative competitive strength of the focal firm, rather than to the competitive intensity in the industry as a whole. Thus, we excluded this item (the inclusion/exclusion of this item has no material effect on the subsequent analysis).

To classify firms as either product or service focused, we generated the dummy variable Service Firm. This variable was based on a question that asked respondents to report the fraction of revenues derived from services the year before. Specifically, respondents were asked: "How was your firm's income last year divided between income based on the sales of services and sales of products? Here, a product is defined as something tangible - something that can be touched. Please enter the percentage of sales from services of the total turnover for last year." As can be seen in Fig. 2, the majority of firms reported receiving revenue only from either products or services, and few firms had significant revenues from both. Therefore, we split the firms into product or service firms based on the fraction of revenue derived from services. To best utilise all the available responses in the main analysis, we generated the Service Firm dummy 


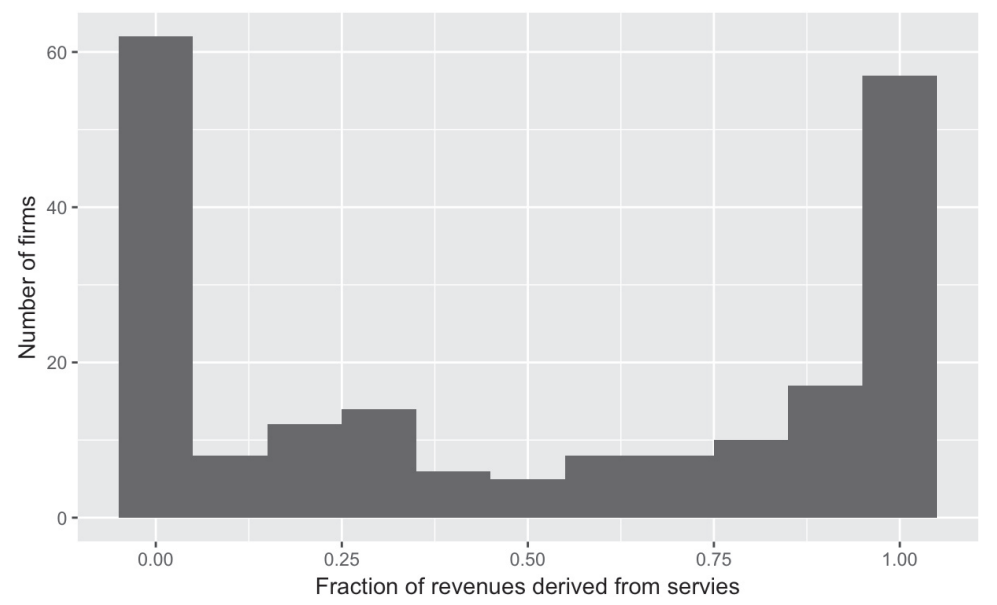

Fig. 2. Histogram of firm revenue distribution between products and services.

variable equal to 1 (service firm) when the ratio was larger than or equal to 0.5 ; otherwise, the dummy variable is 0 (a manufacturing product firm). In subsequent robustness analysis, we classified firms as service firms when the ratio was larger than 0.75 and as product firms when the ratio was smaller than 0.25 , and excluded from the analysis any firms with a ratio between 0.25 and 0.75 .

\section{Results}

Before reporting on the linear regression used for hypotheses tests, we report descriptive and summary statistics for the variables and measures we used.

\section{Descriptive statistics: Overall performance}

The performance variable was based on four questions. Examining first the responses of product firms, we report the individual components of performance in Fig. 3. We found that for the quality component, $50.7 \%$ of the 73 respondents who focused on products agreed or strongly agreed that the quality of their products was higher than their competitors'. For product innovativeness, $44.4 \%$ of respondents agreed or strongly agreed that their firms developed more innovative products than their competitors, and for development speed, the percentage was $40.8 \%$. Finally, for financial performance, $28.2 \%$ of respondents agreed or strongly agreed that their financial performance was better than their competitors' performance. Based on the descriptive characteristics, respondents are quite confident that their firms are doing better than their competitors in relation to product 


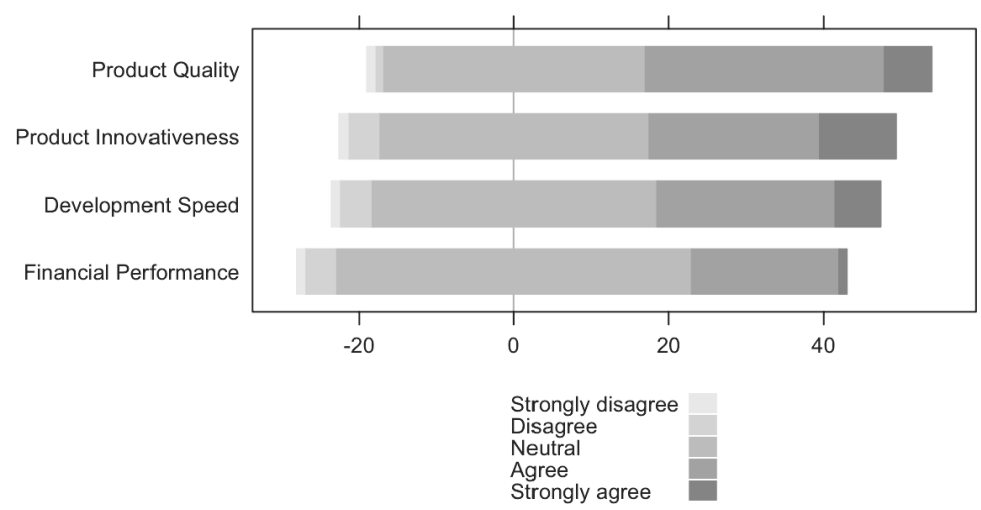

Fig. 3. Reported performance for products.

quality, product innovativeness, and development speed but are least confident about performance.

For service firms, we report on the individual components of the performance measure in Fig. 4. In terms of service quality, $49.4 \%$ of the 89 respondents who focused on service offerings agreed or strongly agreed that the quality of services that they provide was higher than their competitors'. For innovativeness, the corresponding percentage was $36.0 \%$, and for development speed, the percentage was $26.4 \%$. Finally, for financial performance, $24.7 \%$ of respondents agreed or strongly agreed that their financial performance was better than their competitors' performance.

A comparison of Figs. 3 and 4 reveals that for product and service firms, development managers are confident that their firms perform better in terms of quality and innovativeness than competitors, whereas the managers are less confident about their speed to market and financial performance. Generally, the

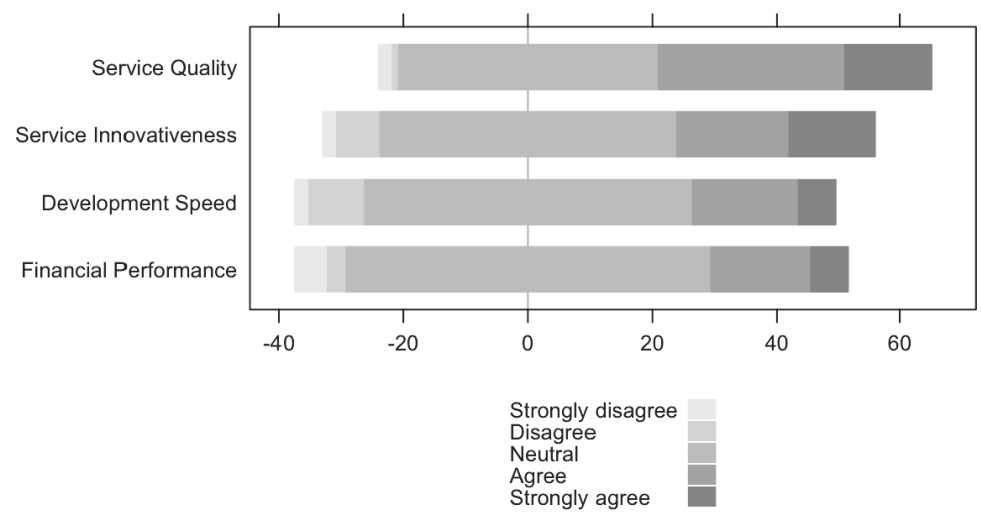

Fig. 4. Reported performance for services. 
reported performance is somewhat higher for services than for products, although there may also be somewhat more uncertainty for services (a higher fraction reported a neutral position).

\section{Descriptive statistics: Customer involvement}

We also report descriptive analysis for the level of customer involvement in different stages, for product and service firms. Figure 5 indicates that the clear majority of product-focused firms involve customers in the idea generation and launch phases of the process, while fewer firms involve customers in the launch phase. As can be seen in the figure, the responses related to the idea generation and development stages are very similar.

The results are similar for service firms. Figure 6 provides some of the main characteristics of customer involvement in service firms in the different stages. The majority of service firms involve customers during the idea generation and development stage of the innovation process, but fewer firms involve customers in the launch stage. Taken together, the results for products and services are similar: Involvement is lower during the launch phase than during the other two phases, and involvement tends to be similar during the idea generation and development stages (see Appendix A for a more detailed analysis of the correlation for these two variables).

\section{Summary statistics and correlations}

Summary statistics and correlations are reported in Table 1 for the variables used in the regression models, as well as for the variable used to distinguish between

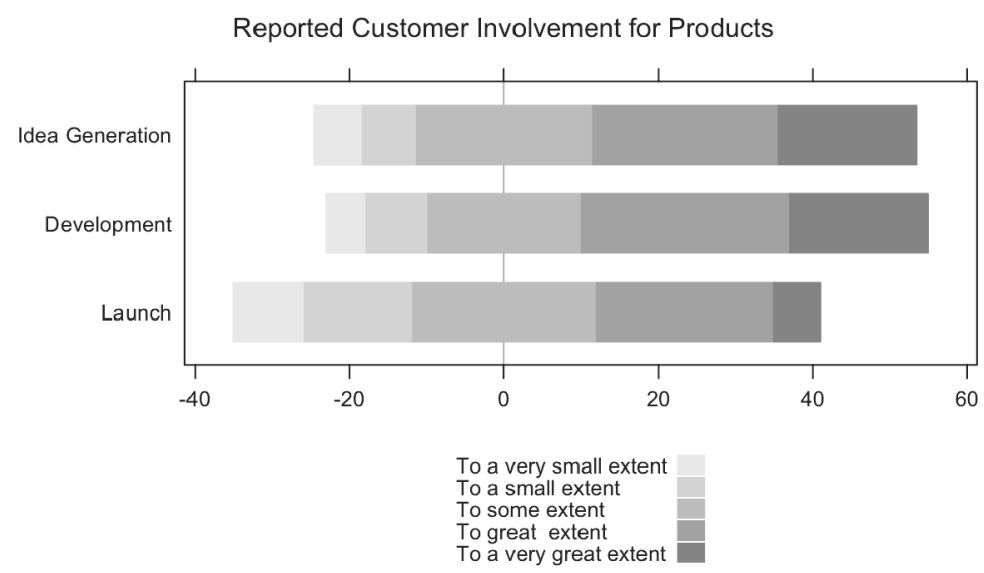

Fig. 5. Reported customer involvement in manufacturing products. 


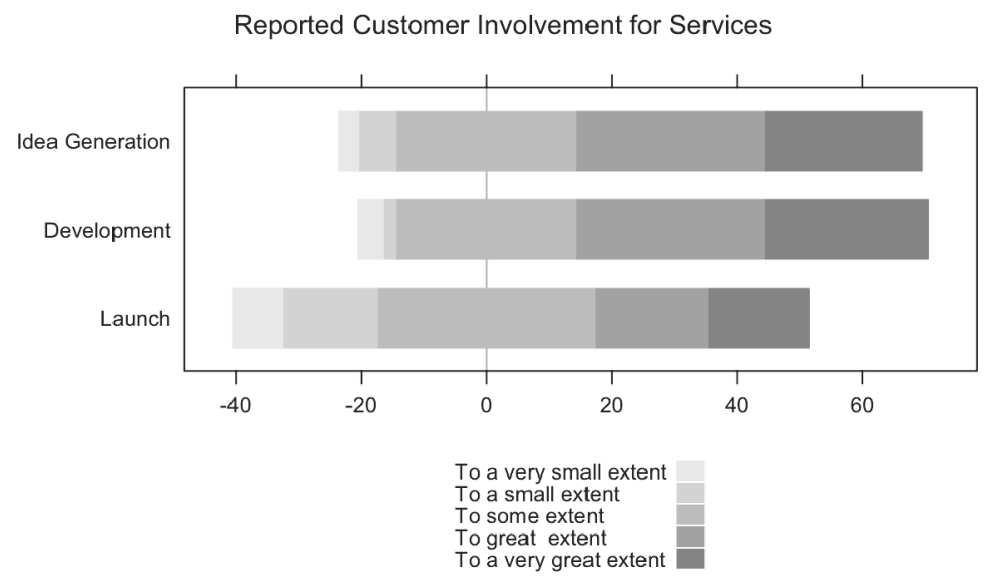

Fig. 6. Reported customer involvement in different stages of new services.

product and service firms. The correlations are generally moderate; the largest correlation is between customer involvement in early and late stages (Involvement in IG and Dev Phases and Involvement in the Launch Phase, $r=0.51$, $p<0.01)$. There are no statistically significant bivariate correlations between Fraction of Rev from Services, which is used to distinguish between product and service firms, and other variables. Variance inflation factor (VIF) values and tolerance values indicate that multicollinearity assumptions are not violated. The VIF values range from 1.04 to 1.5 , and therefore, in all cases are below the generally accepted cut-off of 10 . In addition, tolerance values for independent variables in all models are well above the generally accepted lower bound of 0.10 , ranging from 0.67 to 0.96 . Taken together, these statistics indicate that multicollinearity is not an issue.

Table 1. Descriptive statistics and correlations.

\begin{tabular}{|c|c|c|c|c|c|c|c|c|}
\hline & Mean & SD & Min & Max & (1) & (2) & (3) & (4) \\
\hline Overall Performance (1) & 3.15 & 0.55 & 1 & 5 & & & & \\
\hline $\begin{array}{l}\text { Involvement in IG and Dev } \\
\text { Phases (2) }\end{array}$ & 3.67 & 1.07 & 1 & 5 & $0.21 * *$ & & & \\
\hline $\begin{array}{l}\text { Involvement in Launch } \\
\text { Phase (3) }\end{array}$ & 3.13 & 1.15 & 1 & 5 & $0.28 * * *$ & $0.51 * * *$ & & \\
\hline Competitive Intensity (4) & 3.31 & 0.63 & 1 & 5 & $0.18 *$ & -0.13 & 0.09 & \\
\hline $\begin{array}{l}\text { Fraction of Rev from } \\
\text { Services (5) }\end{array}$ & 0.50 & 0.42 & 0 & 1 & -0.06 & 0.08 & 0.07 & 0.00 \\
\hline
\end{tabular}




\section{Regression models}

OLS regression was used to assess the relationship between the dependent variable, Overall Performance, and the independent variables, Involvement in $I G$ and Dev Phases and Involvement in the Launch Phase. The models generally explain around $10-20 \%$ of the variability in the dependent variable. As can be seen from Table 1, correlations between variables were found to be moderate (after the variables Involvement in $I G$ and Dev Phases were combined), indicating that multicollinearity was not an issue. Additional diagnostic analyses were conducted to ensure no violation of the assumptions of normality, linearity, multicollinearity, and homoscedasticity. We report on these analyses in Appendix B.

In the models in Table 2, the dependent variable in all cases is Overall Performance. Models MP1 and MP2 represent regression results only for firms whose main activity is manufacturing products. Model MP1 includes Involvement in IG and Dev Phases and Involvement in the Launch Phase. The coefficient for Involvement in IG and Dev Phases is not statistically significant when a two-tailed test is used $(p<0.1)$, although it is statistically significant when a one-tailed test is used $(p<0.05)$. Involvement in the Launch Phase seems to have a limited effect for products. In model MP2, Competitive Intensity in the market is included as a control variable. Competitive intensity can affect the overall performance independent of customer involvement, so this is a more appropriate model specification. When this control variable is included, Involvement in $I G$ and Dev Phases is statistically significant $(p<0.05)$, but Involvement in the Launch Phase is not. Taken together, models MP1 and MP2 provide support for hypothesis $\mathrm{H1}$, that customer involvement in the idea generation phase has a positive impact. We do not find evidence that customer involvement in the

Table 2. Regression models.

\begin{tabular}{lcccc}
\hline & MP1 & MP2 & MS1 & MS2 \\
\hline Constant & $2.605^{* *}$ & $2.057^{* *}$ & $2.704^{* *}$ & $2.066^{* *}$ \\
& $(11.539)$ & $(4.302)$ & $(12.102)$ & $(5.838)$ \\
Involvement in IG and Dev Phases & $0.111^{+}$ & $0.148^{*}$ & -0.004 & 0.026 \\
& $(1.714)$ & $(2.154)$ & $(-0.059)$ & $(0.421)$ \\
Involvement in Launch Phase & 0.058 & 0.062 & $0.143^{*}$ & $0.131^{*}$ \\
& $(0.888)$ & $(0.904)$ & $(2.608)$ & $(2.398)$ \\
Competitive Intensity & & 0.123 & & $0.173^{*}$ \\
& & $(1.051)$ & & $(2.146)$ \\
$R$-squared & 0.1 & 0.1 & 0.1 & 0.2 \\
$N$ & 71 & 69 & 89 & 88 \\
\hline
\end{tabular}

Notes: (Significance levels: $\left({ }^{+},{ }^{*},{ }^{* *},{ }^{* * *}\right)=(p<0.10, p<0.05, p<0.01, p<0.001)$. 
launch phase has an impact on firms that focus on products. Furthermore, the point estimate is larger for the idea generation phase than for the launch phase, as predicted by hypothesis $\mathrm{H} 2$, although the difference does not reach statistical significance when a Wald test is used to compare the two coefficients. Finally, hypothesis H4 (which involves only service firms) is not directly applicable to these models.

Models MS1 and MS2 are similar to models MP1 and MP2, but include only firms whose main activity is delivering services. In model MS1, the coefficient for Involvement in IG and Dev Phases is not statistically significant. The coefficient for Involvement in the Launch Phase is statistically significant $(p<0.05)$. In model MS2, Competitive Intensity is included as a control variable. The coefficients are similar as in model MS1; the coefficient for Involvement in IG and Dev Phases is not statistically significant, but the coefficient for Involvement in the Launch Phase is statistically significant $(p<0.05)$. Taken together, models MS1 and MS2 provide support for hypothesis $\mathrm{H} 3$, that customer involvement in the launch stage has a positive impact. We do not find evidence that customer involvement in the idea generation and development phases has an impact for firms that focus on services. When comparing the idea generation and launch phases in service firms, we find, in contrast with product firms, that the point estimate is larger for the launch phase than for the idea generation phase, although the difference does not reach statistical significance when a Wald test is used. Finally, H2 (which involves only manufacturing firms) is not directly applicable to these models.

A given firm may not engage purely in the development of new products or new services, either because the firm develops a mix of product offerings and service offerings, or because the firm develops offerings that are hybrids between products or services. To ensure that the results and observed patterns were not due to firms with mixed or hybrid offerings, we performed robustness analysis where we excluded all firms whose reported fraction derived from services was between $25 \%$ and $75 \%$. In Table 3, we report regression results that are comparable to the main regression results, but which include only firms that can be clearly categorised as either product or service firms. We do this by including as product firms only those that report that more than $75 \%$ of their revenues are derived from products, and only including as service firms those that report that more than $75 \%$ of their revenues are derived from services. Any firms whose reported fraction lies between $25 \%$ and $75 \%$ are discarded. In the table, MPS stands for models for firms with strong product focus, whereas MSS stands for firms with a strong service focus. The results shown in the table are substantively very similar to the results of the main analysis, and all patterns relating to the hypotheses are identical. 
Table 3. Regressions including only firms with strong product or service focus.

\begin{tabular}{lcccc}
\hline & MPS1 & MPS2 & MSS1 & MSS2 \\
\hline Constant & $2.767^{* *}$ & $2.602^{* *}$ & $2.669^{* *}$ & $2.137^{* *}$ \\
& $(11.558)$ & $(4.866)$ & $(10.535)$ & $(5.566)$ \\
Involvement in IG and Dev Phases & $0.151^{*}$ & $0.167^{*}$ & -0.033 & -0.006 \\
& $(2.150)$ & $(2.272)$ & $(-0.452)$ & $(-0.089)$ \\
Involvement in Launch Phase & -0.038 & -0.021 & $0.178^{*}$ & $0.160^{*}$ \\
& $(-0.522)$ & $(-0.275)$ & $(2.797)$ & $(2.468)$ \\
Competitive Intensity & & 0.016 & & 0.152 \\
& & $(0.117)$ & & $(1.660)$ \\
$R$-squared & 0.091 & 0.111 & 0.115 & 0.165 \\
$N$ & 55 & 53 & 73 & 72 \\
\hline
\end{tabular}

Notes: Significance levels: $\left({ }^{+},{ }^{*},{ }^{* *},{ }^{* * *}\right)=(p<0.10, p<0.05, p<0.01, p<0.001)$.

Looking at all the models together, a different pattern emerges for products and services. When developing new products, customer involvement in the idea generation and development phases is beneficial for overall performance, but customer involvement in the launch phase has little effect. When developing new services, the opposite is the case: Customer involvement in the launch phase is beneficial for the overall performance of services, but customer involvement in the idea generation and development phases has little effect. Taken together, the patterns are directionally consistent with the predictions of $\mathrm{H} 2$ and $\mathrm{H} 4$, although tests for the difference of estimated coefficients did not reach statistical significance when a Wald test was used. We find support for $\mathrm{H} 1$, regarding the benefit of customer involvement in the idea generation phase, only for product firms, and we find support for $\mathrm{H} 3$, regarding the benefit of customer involvement in the launch phase, only for service firms. In contrast to the idea that customer involvement in either stage is important for firms in general, the results suggest that the optimal timing of involvement may differ for firms involved in developing and launching products on one hand and services on the other. When the timing of customer involvement does not fit the type of solution being developed, customer involvement seems to be of limited benefit.

\section{Discussion and Conclusion}

The purpose of this study was to understand better the effect of customer involvement in various stages of development for product-focused firms on one hand and service-focused firms on the other. A number of previous studies have found positive effects of involvement, in particular in the early stages, where idea 
generation takes place (Alam and Perry, 2002; Witell et al., 2014), and later, in the launch stage (Chang and Taylor, 2016). We hypothesised that the nature of what is being developed was important to how customer involvement supports the development process. In particular, we argued that because the features of products become difficult to change after the development phase, early customer involvement becomes especially important for product-focused firms. When developing services, however, we argued that involvement in the launch phase is more important, because services are more malleable throughout the life cycle, and early-stage involvement even has the potential to lead to over-customisation, and because interaction with the customer is a very natural part of launching a service.

In the quantitative analysis, we found that product performance increases with customer involvement in the idea generation and development phases, but later involvement, in the launch phase, had little or no effect (after controlling for early involvement). These findings are consistent with Witell et al.'s (2014) findings, and partially in line with Gruner and Homburg's (2000) findings. For services, the opposite was true: We found that service performance increases with customer involvement in the launch phase, but earlier involvement, in the idea generation and development phases, had little or no effect (after controlling for late involvement). The study makes several noteworthy contributions regarding customer involvement in the innovation process. We partially confirmed the findings from Gruner and Homburg (2000) and Chang and Taylor (2016) who argued that customer involvement has a positive influence in the idea generation and launch phases. More importantly, we provide suggestive evidence of how customer involvement has a differential effect on the development of products versus services.

Taken together, these findings suggest that customers play a role in firms' project performance and potentially in firms' overall performance. The findings highlight the importance of customer involvement in the development of new products and services in the idea generation and launch phases of the process, but also of understanding how the timing of customer involvement interacts with what the firm is developing. By involving customers in the process, managers and firms better understand customer needs, wants, desires, likes, and dislikes. By understanding current and perhaps future customer needs, firms can develop new or improve existing products and services and better fulfill the needs of current and potential customers.

This study extends existing knowledge regarding customer involvement in the early stages of the development of products and services, and in the launch phase, by highlighting the different benefits and costs for customer involvement for 
products and services. Some papers have examined how the benefits of customer involvement differ according to product innovativeness (Lin et al., 2013), and according to innovation capabilities (Menguc et al., 2014). We apply similar insights to the relationship between products and services.

\section{Limitations and future research}

This study has several limitations. First, because the data are based on surveys that were administered to managers within the firms, it is not possible to rule out common method bias. The pattern of results that we find alleviates those concerns to some extent, because there is no particular reason to expect such a bias to affect respondents from product-focused firms differently from respondents from servicefocused firms. Using revenues or contribution margins to judge the performance of innovation projects would be an ideal solution to this issue, but getting access to accounting data for a large number of firms is difficult. Second, although the results are overall very consistent with the hypotheses, directionally and in terms of the statistical significance of the main effects, a Wald test of coefficient differences did not reach conventional statistical significance levels. Third, the firms studied here are all located in the same market, and although we are not aware of any idiosyncrasies that would lead us to expect the patterns we found to be substantively different in other markets, it is impossible to conclusively rule this out. We hope that researchers will perform similar designs with data from other markets to explore whether the patterns are similar there.

\section{Implications and conclusions}

The study has implications for the theoretical view of customer involvement and for future research in the field. One interesting avenue of future research which is implied by these results is to study customer involvement using a more detailed breakdown of firm focus. We relied on a separation into product-focused firms and service-focused firms, but we were not able to break the sample down further by product categories or industries. In addition, although the distinction between products and services is important, it is not the only distinction. For example, it is not unlikely that issues related to the supply chain and the method of delivery for products affect how malleable they are, and this may result in differences in the optimal phase for customer involvement.

Another avenue of future research is to examine in detail the involvement of customers in firms that develop hybrid offerings that may share a number of characteristics with products and services. It is possible that the results for hybrid 
offerings would simply lie between what is observed for products and what is observed for services. However, it may also be the case that there are particular challenges in obtaining user input for offerings that contain elements of products and services, due to the potentially complex interactions between the two. The case of customer involvement in hybrids deserves theoretical and empirical attention, and we hope that such studies can benefit from the present study.

In terms of practical implications, even if the results suggest that the benefit of involvement may differ between phases for product versus service firms, this was not reflected in the descriptive statistics of the levels of involvement in different stages. On the contrary, product firms and service firms report higher levels of involvement in the idea generation and development phases than in the launch stage. This result may indicate an opportunity for service firms, which tended to report higher involvement in the earlier phases, despite the evidence that for such firms, involvement in the later phases may in fact be more beneficial for project performance. Therefore, service firms might be able to improve their project performance by shifting the emphasis of customer involvement to somewhat later in the product development cycle. Ideally, such a shift would be accompanied by a detailed study of the performance implications of the change.

Another practical implication may lie with the support mechanisms that are utilised when customer input is sought. As we note above, in the section on the conceptual frameworks, researchers have highlighted a number of issues that may affect the costs and benefits of customer involvement. A potential issue that can reduce the benefits of customer involvement is the difficulty of visualising the use of a given offering early in the development life cycle. The use of early prototypes can alleviate this problem, and is widely used, especially in the case of the development of new products. However, recent research has examined in particular the prototyping of services (Blomkvist, 2014), and one way in which firms that are developing new service offerings could increase the benefits of customer involvement would be to increase the formal use of service prototyping. In addition to allowing more focused feedback early on, service prototyping may alleviate drawbacks associated with over-customisation because the prototype allows the developers of a new service to create a unified vision of what the final service will look like for employees and customers.

In this study, we sought to improve the theoretical, empirical, and practical understanding of how the optimal approach to customer involvement depends on what exactly is being developed. We feel that adding to the knowledge about these interactions between the phase of involvement and what is being developed has important implications for practice and for future research in the field. Harnessing the benefits of customer involvement in more circumstances has the 
potential to increase the quality and innovativeness of new product and new service offerings.

\section{Appendix A. Variable Construction}

\section{A.1. Combining independent variables idea generation and development due to high correlation}

Figure A.1 shows that the responses about involvement in the idea generation phase are very similar to the responses about involvement in the development phase. The correlation between the variables is also very high $(r=0.94$, $p<0.01)$. This result suggests that the firms in the sample tend to follow very similar policies regarding customer involvement in the idea generation and development phases. Therefore, it is appropriate to combine those variables into one for further analysis (we use the mean of the two variables).

\section{A.2. Customer involvement in the launch stage}

Figure A.2 shows that the responses about involvement in the idea generation and development phases differ considerably from the responses about involvement in the launch phase. The correlation between the two variables is moderate $(r=0.51$, $p<0.01)$. This result suggests that in general, firms in the sample tend to follow distinct policies when it comes to customer involvement in the idea generation and development phases and in the launch phase. Therefore, it is appropriate to perform analysis on those variables separately.

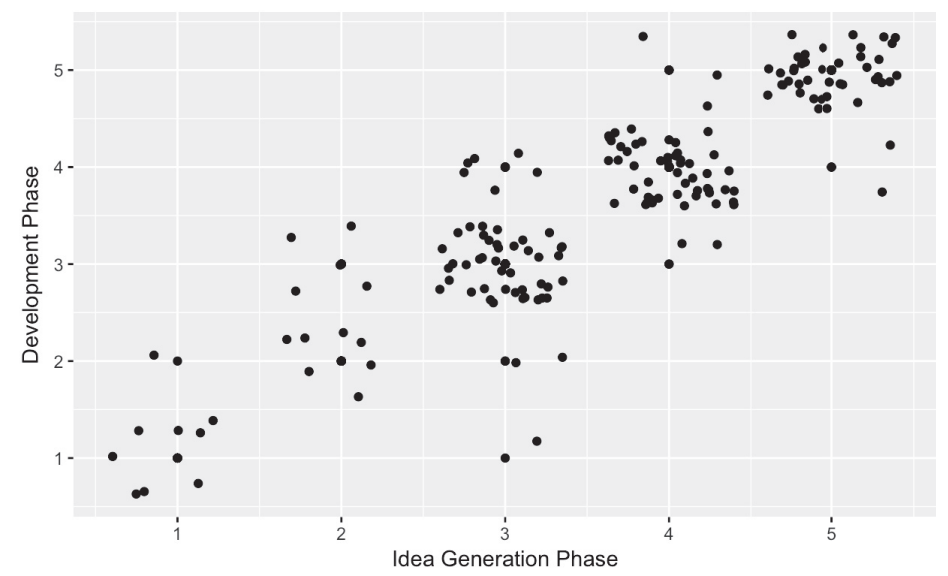

Fig. A.1. Joint distribution of reported customer involvement in the Idea Generation and Development phases. Because the actual reported values are discrete, the figure includes a small amount of jitter to distinguish between identical observations. 


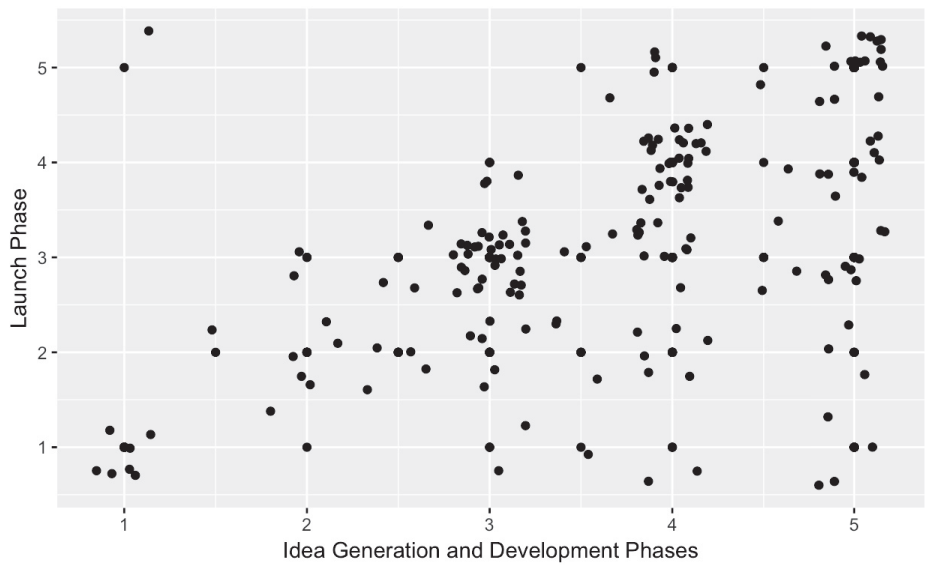

Fig. A.2. Joint distribution of reported customer involvement in the Idea Generation and Development phases. Because the actual reported values are discrete, the figure includes a small amount of jitter to distinguish between identical observations.

\section{Appendix B. Diagnostic Analysis related to Regression Analysis}

Diagnostic analysis was performed to evaluate model assumptions. Diagnostic results were similar across different model specifications. We report diagnostic results for a model using all observations and all independent variables. The correlations, tolerance, and VIFs are moderate; thus, there is no violation of the

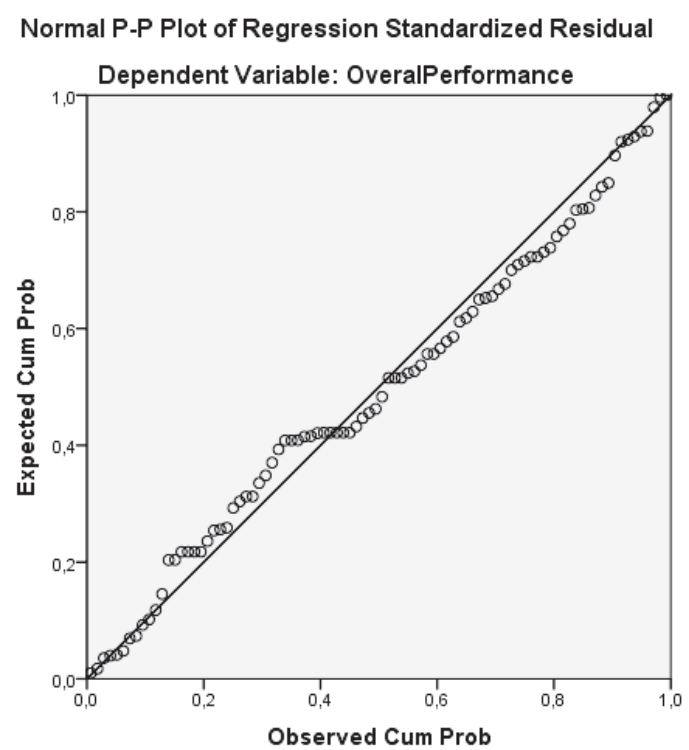

Fig. B.1. Normal P-P Plot for regression analysis. 


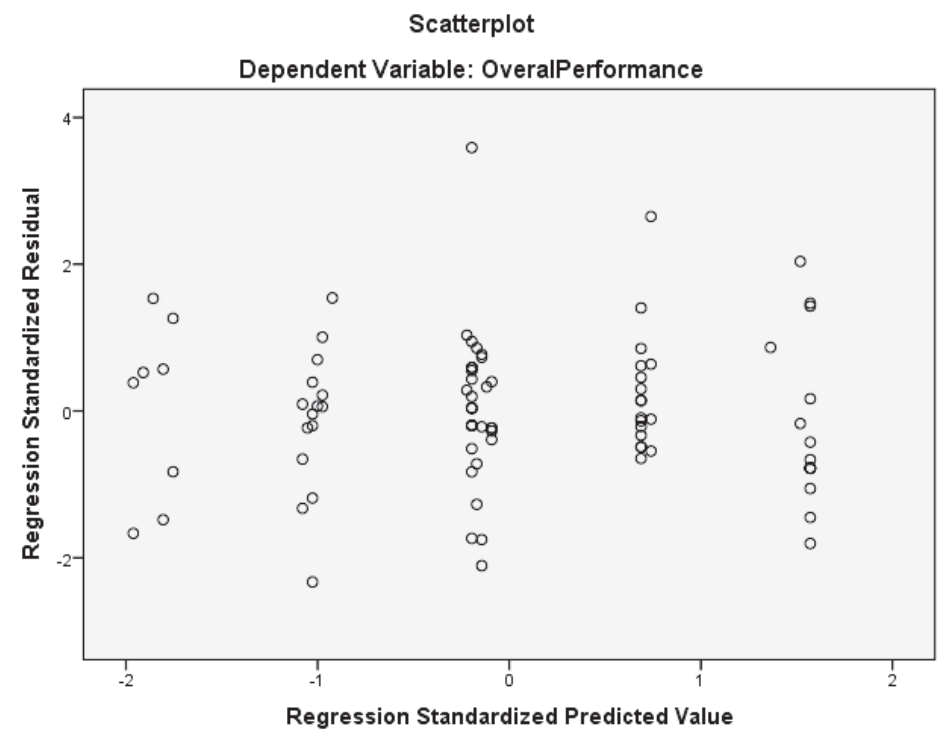

Fig. B.2. Scatterplot of residuals according to the predicted values.

multicollinearity assumptions. The VIF values in all models for the independent variables are well below the cut-off of 10. The VIF values range from 1.04 (the lowest value) to 1.50 (the highest value). In addition, the tolerance values for the independent variables in all models are well above 0.10 . The tolerance values range from 0.67 to 0.96 , indicating that multicollinearity is not an issue.

Figure B.1 shows a Normal P-P Plot for the model. The points lie in a reasonably straight diagonal line from the bottom left to the top right. As can be seen, there are no major deviations from the line. The corresponding scatterplot, shown in Fig. B.2, shows that most of the scores cluster around the centre along the 0 point.

\section{Appendix C. Questionnaire and Measure Validation}

Below, we present an overview of the questionnaire survey, as well as the measures of validity and reliability statistics for each variable construct. For measure validation, we used confirmatory factor analysis.

The Kaiser-Meyer-Olkin (KMO) measure of sampling adequacy value is greater than 0.6 , and the Barlett test is statistically significant $(p<0.001)$. Anything above 0.5 is acceptable although a value above 0.6 is preferred. Therefore, the results imply that factor analysis is appropriate. In the correlation matrix, there is a considerable number of coefficients greater than 0.3 and above, which also suggests that it is appropriate to conduct factor analysis. 
Table C.1. Constructs, questions, and reliability statistics.

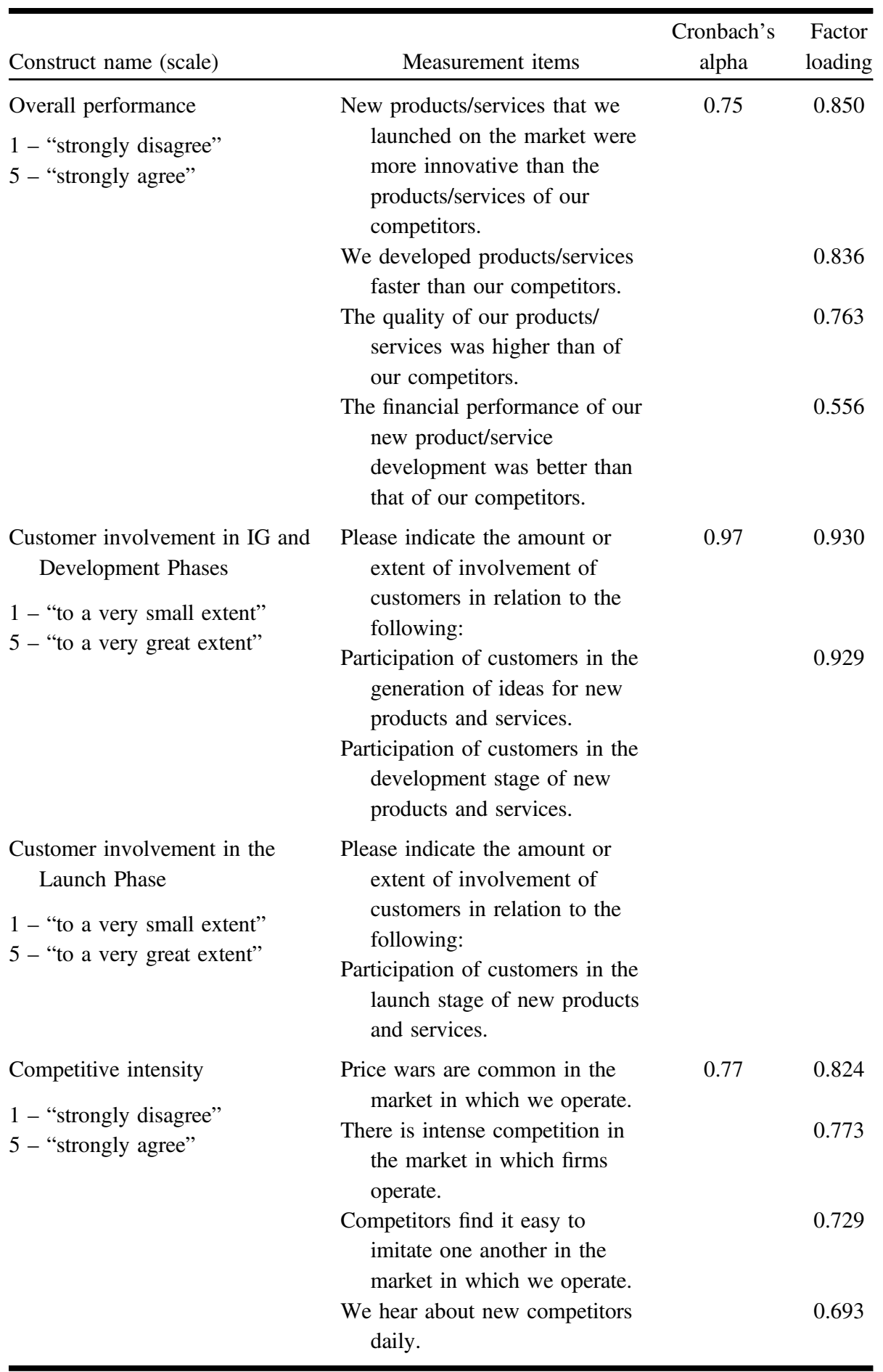


Table C.1. (Continued)

\begin{tabular}{|c|c|c|c|}
\hline Construct name (scale) & Measurement items & $\begin{array}{l}\text { Cronbach's } \\
\text { alpha }\end{array}$ & $\begin{array}{l}\text { Factor } \\
\text { loading }\end{array}$ \\
\hline Fraction of revenue from services & $\begin{array}{l}\text { How was your firm's income last } \\
\text { year divided between income } \\
\text { based on the sales of services } \\
\text { and sales of products? Here, a } \\
\text { product is defined as } \\
\text { something tangible- } \\
\text { something that can be } \\
\text { touched. Please enter the } \\
\text { percentage of sales from } \\
\text { services of the total turnover } \\
\text { for the last year. }\end{array}$ & & \\
\hline
\end{tabular}

As can be seen in the table below, each item also loads high for the component or factor.

For all constructs with more than one item, the alpha coefficient of reliability was calculated and evaluated. For the majority of constructs, the alpha coefficient was higher than 0.7 suggesting strong internal consistency among the items that were used.

\section{Acknowledgements}

We would like to thank Marina Candi for generous assistance and advice. This research was funded in part by the Icelandic Research Fund.

\section{References}

Al-Zu'bi, ZbMF and C Tsinopoulos (2012). Suppliers versus lead users: Examining their relative impact on product variety. Journal of Product Innovation Management, 29(4), 667-680. doi: 10.1111/j.1540-5885.2012.00932.x.

Alam, I (2002). An exploratory investigation of user involvement in new service development. Journal of the Academy of Marketing Science, 30(3), 250-261.

Alam, I (2006). Removing the fuzziness from the fuzzy front-end of service innovations through customer interactions. Industrial Marketing Management, 35(4), 468-480.

Alam, I (2013). Customer interaction in service innovation: Evidence from India. International Journal of Emerging Markets, 8(1), 41-64. doi: 10.1108/ 17468801311297273. 
Alam, I and C Perry (2002). A customer-oriented new service development process. The Journal of Services Marketing, 16(6), 515-534.

Avlonitis, GJ and SP Gounaris (1999). Marketing orientation and its determinants: An empirical analysis. European Journal of Marketing, 33(11/12), 1003-1037.

Baines, TS, HW Lightfoot, O Benedettini and JM Kay (2009). The servitization of manufacturing: A review of literature and reflection on future challenges. Journal of Manufacturing Technology Management, 20(5), 547-567.

Blazevic, V and A Lievens (2008). Managing innovation through customer coproduced knowledge in electronic services: An exploratory study. Journal of the Academy of Marketing Science, 36(1), 138-151. doi: 10.1007/s11747-007-0064-y.

Blomkvist, J (2014). Representing Future Situations of Service: Prototyping in Service Design, Doctoral Dissertation, Linköping University Electronic Press.

Candi, M, J van den Ende and G Gemser (2015). Benefits of customer codevelopment of new products: The moderating effects of utilitarian and hedonic radicalness. Journal of Product Innovation Management, doi: 10.1111/jpim.12286.

Carbonell, P, AI Rodríguez-Escudero and D Pujari (2009). Customer involvement in new service development: An examination of antecedents and outcomes. Journal of Product Innovation Management, 26(5), 536-550. doi: 10.1111/j.1540-5885. 2009.00679.x.

Chang, W and SA Taylor (2016). The effectiveness of customer participation in new product development: A meta-analysis. Journal of Marketing, 80(1), 47-64. doi: 10.1509/jm.14.0057.

Cohen, WM and DA Levinthal (1990). Absorptive capacity: A new perspective on learning and innovation. Administrative Science Quarterly, 35(1), 128-152.

Dabholkar, PA (2015). How to improve perceived service quality by increasing customer participation. In Proceedings of the 1990 Academy of Marketing Science (AMS) Annual Conf., BJ Dunlap (Ed.), Cham, Switzerland: Springer International, pp. 483-487.

Dadfar, H, S Brege and SE Sedigheh (2013). Customer involvement in service production, delivery and quality: The challenges and opportunities. International Journal of Quality and Service Sciences, 5(1), 46-65. doi: 10.1108/17566691311316248.

Edvardsson, B, A Gustafsson, P Kristensson and L Witell (2010). Customer integration in service innovation. In The Handbook of Innovation and Services: A Multi-Disciplinary Perspective, F Gallouj and F Djellal (Eds.), pp. 301-317. Cheltenham, England: Elgar.

Fuchs, C and M Schreier (2011). Customer empowerment in new product development. Journal of Product Innovation Management, 28(1), 17-32. doi: 10.1111/j.1540-5885. 2010.00778.x.

Gallouj, F and M Savona (2010). Towards a theory of innovation in services: A state of the art. In The Handbook of Innovation and Services: A Multi-Disciplinary Perspective, F Gallouj and F Djellal (Eds.), pp. 27-48. Cheltenham, England: Elgar.

Gassmann, O, C Kausch and E Enkel (2010). Negative side effects of customer integration. International Journal of Technology Management, 50(1), 43-63. 
Good, DJ (1990). Utilizing consumer involvement to market services. Review of Business, 11(4), 3.

Gruner, KE and C Homburg (2000). Does customer interaction enhance new product success? Journal of Business Research, 49(1), 1-14.

Gustafsson, A, P Kristensson and L Witell (2012). Customer co-creation in service innovation: A matter of communication? Journal of Service Management, 23(3), 311-327.

Herstatt, C, C Stockstrom, B Verworn and A Nagahira (2006). "Fuzzy front end" practices in innovating Japanese companies. International Journal of Innovation \& Technology Management, 3(1), 43-60.

Hoyer, WD, R Chandy, M Dorotic, M Krafft and SS Singh (2010). Consumer cocreation in new product development. Journal of Service Research, 13(3), 283-296.

Ind, N and N Coates (2013). The meanings of co-creation. European Business Review, 25(1), 86-95. doi: 10.1108/09555341311287754.

Jaworski, BJ and AK Kohli (1993). Market orientation: Antecedents and consequences. The Journal of Marketing, 57(3), 53-70.

Kaplan, AM and M Haenlein (2006). Toward a parsimonious definition of traditional and electronic mass customization. Journal of Product Innovation Management, 23(2), 168-182.

Knudsen, MP (2007). The relative importance of interfirm relationships and knowledge transfer for new product development success. Journal of Product Innovation Management, 24(2), 117-138. doi: 10.1111/j.1540-5885.2007.00238.x.

Kotler, P, V Wong, J Saunders and G Armstrong (2005). Principles of Marketing, 4th edn. Harlow, England: Pearson Prentice Hall.

Kristensson, P, A Gustafsson and T Archer (2004). Harnessing the creative potential among users. Journal of Product Innovation Management, 21(1), 4-14.

$\mathrm{Ku}, \mathrm{EC}, \mathrm{W} \mathrm{Wu}$ and YJ Chen (2016). The relationships among supply chain partnerships, customer orientation, and operational performance: The effect of flexibility. Information Systems and eBusiness Management, 14(2), 415-441. doi: 10.1007/s10257015-0289-0.

Lai, KH and CW Wong (2012). Green logistics management and performance: Some empirical evidence from Chinese manufacturing exporters. Omega, 40(3), 267-282.

Lengnick-Hall, CA (1996). Customer contributions to quality: A different view of the customer-oriented firm. Academy of Management. The Academy of Management Review, 21(3), 791.

Lin, MJ, Y Tu, D Chen and C Huang (2013). Customer participation and new product development outcomes: The moderating role of product innovativeness. Journal of Management and Organization, 19(3), 314-337. doi: 10.1017/jmo.2013.8.

Magnusson, PR (2003). Benefits of involving users in service innovation. European Journal of Innovation Management, 6(4), 228-238.

Mahr, D, A Lievens and V Blazevic (2014). The value of customer cocreated knowledge during the innovation process. Journal of Product Innovation Management, 31(3), 599-615. doi: 10.1111/jpim.12116. 
Matthing, J, B Sanden and B Edvardsson (2004). New service development: Learning from and with customers. International Journal of Service Industry Management, 15(5), 479-498.

Menguc, B, S Auh and P Yannopoulos (2014). Customer and supplier involvement in design: The moderating role of incremental and radical innovation capability. Journal of Product Innovation Management, 31(2), 313-328. doi: 10.1111/jpim.12097.

Ng, I, G Parry, L Smith, R Maull and G Briscoe (2012). Transitioning from a goodsdominant to a service-dominant logic: Visualising the value proposition of RollsRoyce. Journal of Service Management, 23(3), 416-439.

Nishikawa, H, M Schreier and S Ogawa (2013). User-generated versus designer-generated products: A performance assessment at Muji. International Journal of Research in Marketing, 30(2), 160-167. doi: 10.1016/j.ijresmar.2012.09.002.

Ordanini, A and A Parasuraman (2011). Service innovation viewed through a servicedominant logic lens: A conceptual framework and empirical analysis. Journal of Service Research: JSR, 14(1), 3.

Ostrom, AL, MJ Bitner, SW Brown, KA Burkhard, M Goul, V Smith-Daniels and E Rabinovich (2010). Moving forward and making a difference: Research priorities for the science of service. Journal of Service Research, 13(1), 4-36. doi: 10.1177/ 1094670509357611.

Prahalad, CK and V Ramaswamy (2004a). Co-creating unique value with customers. Strategy \& Leadership, 32(3), 4-9.

Prahalad, CK and V Ramaswamy (2004b). Co-creation experiences: The next practice in value creation. Journal of Interactive Marketing, 18(3), 5-14.

Rathmell, JM (1966). What is meant by services? Journal of Marketing, 30(4), 32-36.

Reim, W, V Parida and D Örtqvist (2015). Product-Service Systems (PSS) business models and tactics-a systematic literature review. Journal of Cleaner Production, 97, 61-75.

Salter, A and BS Tether (2006). Innovation in services: Through the looking glass of innovation studies. Background paper for Advanced Institute of Management (AIM) Research's Grand Challenge on Service Science.

Sigala, M (2012). Social networks and customer involvement in new service development (NSD). International Journal of Contemporary Hospitality Management, 24(7), 966-990. doi: 10.1108/09596111211258874.

Thomke, S and E von Hippel (2002). Customers as innovators: A new way to create value. Harvard Business Review, 80(4), 74-81.

Ulwick, AW and D Leonard (2002). Turn customer input into innovation. Harvard Business Review, 80(1), 91-97.

Vargo, SL and RF Lusch (2004a). Evolving to a new dominant logic for marketing. Journal of Marketing, 68(1), 1-17.

Vargo, SL and RF Lusch (2004b). The four service marketing myths: Remnants of a goods-based, manufacturing model. Journal of Service Research: JSR, 6(4), 324-335. 
Wang, Y, J Wu and Z Yang (2013). Customer participation and project performance: The mediating role of knowledge sharing in the Chinese telecommunication service industry. Journal of Business-to-Business Marketing, 20(4), 227-244. doi: 10.1080/ 1051712X.2013.840820.

Witell, L, A Gustafsson and D Johnson (2014). The effect of customer information during new product development on profits from goods and services. European Journal of Marketing, 48(9/10), 1709. 